Comparative Philosophy Volume 3, No. 1 (2012): 03-29

Open Access / ISSN 2151-6014

www.comparativephilosophy.org

\title{
HOW IS THIS PAPER PHILOSOPHY?
}

\author{
KRISTIE DOTSON
}

\begin{abstract}
This paper answers a call made by Anita Allen to genuinely assess whether the field of philosophy has the capacity to sustain the work of diverse peoples. By identifying a pervasive culture of justification within professional philosophy, I gesture to the ways professional philosophy is not an attractive working environment for many diverse practitioners. As a result of the downsides of the culture of justification that pervades professional philosophy, I advocate that the discipline of professional philosophy be cast according to a culture of praxis. Finally, I provide a comparative exercise using Graham Priest's definition of philosophy and Audre Lorde's observations of the limitations of philosophical theorizing to show how these two disparate accounts can be understood as philosophical engagement with a shift to a culture of praxis perspective.
\end{abstract}

Keywords: professional philosophy, diversity, culture of justification, culture of praxis, exceptionalism, sense of incongruence, Audre Lorde, Graham Priest, Anita Allen, Gayle Salamon

Philosophy is not for black women. That is a white man's game.

- College Guidance Counselor at a Historically Black College (2009)

\section{INTRODUCTION}

My younger sister, Alexis Ford, once had the following conversation with her Guidance Counselor, while she was a college student at a Historically Black College.

Counselor: Why don't you major in Social Work?

Alexis: Social Work sounds good, but I am interested in philosophy.

Counselor: (Snorts) Philosophy is not for black women. That's a white man's game.

Alexis: My older sister is a philosophy professor.

Counselor: Well, she's probably the only one and that should tell you something. (2009)

I remember clearly when this conversation was relayed to me. At the time, I was at once vastly appalled and silently relieved. Appalled at the intentionally discouraging

DOTSON, KRISTIE: Assistant Professor, Department of Philosophy, Michigan State University, USA. Email: dotsonk@msu.edu 
remarks towards my sister's initial interests on the sole basis that she is a black woman. And relieved because, to be honest, this initial resistance led her to seriously reconsider a career in philosophy. At the time, I was not certain that I would recommend a career in professional philosophy for her. In my ensuing conversations with Alexis, it became clear to me that no matter how offensive and inappropriate the Counselor's words were, and they were that, I recognized an uncomfortable sense of déjà vu. Philosophy is seen as a "white man's game" and I am often made to feel a sense of incongruence as a result of that impression. And though I am certainly not the only black woman philosophy professor, as the Counselor assumed in a tongue and cheek fashion, our numbers are still very small. According to Kathryn Gines, fewer than 30 black women hold Ph.D.s in philosophy and also work within philosophy departments in North America (2011, 435). If we were to count the number of black women with research arms in black feminism, one of my primary areas of research, with Ph.D.s in philosophy working within philosophy departments, that number would grow starkly smaller to something like roughly 8 people. As the Counselor suggests, these numbers do tell a story, but what?

Anita L. Allen has issued a challenge to honestly interrogate the origin of the abysmal numbers of black women in the U.S. working in professional philosophy. Specifically, she calls for a genuine assessment of the merits of pursuing a career in philosophy for black women. Allen asks:

With all due respect, what does philosophy have to offer to Black women? It's not obvious to me that philosophy has anything special to offer Black women today. I make this provocative claim to shift the burden to the discipline to explain why it is good enough for us; we should be tired of always having to explain how and prove that we are good enough for the discipline. (Yancy 1998, 172, italics in original)

Allen's skepticism here is similar to the skepticism held in the "advice" from the Guidance Counselor and is most likely intimately tied to my feelings of abject relief when my sister decided to embark on a different career path. In fact, we, i.e. Allen, the Counselor and myself, may all hold a great deal of skepticism towards the ability of professional philosophy to offer an environment where black women can thrive, though for very different reasons. This skepticism is not, as Allen and I are aware, though the Counselor is most likely unaware, a doubt centered on whether black women are good enough to do philosophy. Of course, we are. But we doubt whether the environment provided by professional philosophy is good enough for us. As such, Allen's call that we scrutinize the environment of professional philosophy for its ability to foster the success of Black women marks an important shift away from justifications of Black philosophy, Africana philosophy, and/or black philosophers (See Jones 1977-1978, West 1995, Outlaw and Roth 1997, Outlaw 1997) to an interrogation into the conditions that facilitate or hinder the success of diverse practitioners within professional philosophy as such.

Allen's shift in focus is in line with Robert Solomon's claim that "our critical scrutiny today should be turned on the word 'philosophy' itself...to realize that what 
was once a liberating concept has today become constricted, oppressive, and ethnocentric" (Solomon 2001, 101). Solomon, here, calls for an interrogation into prevailing definitions of philosophy, which may work to exclude and/or suppress diverse perspectives. Both Allen and Solomon draw attention to the possibility that professional philosophy may provide poor conditions for diverse peoples and perspectives. It is in honoring the call to assess the environment of professional philosophy and the possibility of constrictive understandings of philosophy that I turn to genuinely assess the potential of being sustained within professional philosophy as a diverse practitioner. I understand the phrase 'diverse practitioner of philosophy' to refer to notoriously under-represented populations within western, academic philosophy. As a result, my use of 'diversity' here is meant to include not only racial, ethnic, gendered, sexual, and ability diversity, but to also include diverse approaches to philosophy, Eastern, applied, engaged, fieldwork, field, public, experimental, literary approaches, etc. Though the specific challenges within professional philosophy may differ among these diverse populations, the general challenges presented by the environment of professional philosophy and constrictive definitions of philosophy are similar. ${ }^{1}$

My cluster of concerns about the environment of professional philosophy and constrictive definitions of philosophy can be viewed by interrogating the question, "How is this paper philosophy?" To be clear, I am not concerned with appropriate answers to the question, "how is this paper philosophy?" Rather, I am concerned with the kind of disciplinary culture that renders such a question of paramount importance. Specifically, I take the question of how this or that paper is philosophy to betray at least one circumstance that pervades professional philosophy. It points to the prevalence of a culture of justification. Typified in the question, "how is this paper philosophy," is a presumption of a set of commonly held, univocally relevant, historical precedents that one could and should use to evaluate answers to the question. By relying upon, a presumably, commonly held set of normative, historical precedents, the question of how a given paper is philosophy betrays a value placed on performances and/or narratives of legitimation. Legitimation, here, refers to practices and processes aimed at judging whether some belief, practice, and/or process conforms to accepted standards and patterns, i.e. justifying norms. A culture of justification, then, on my account, takes legitimation to be the penultimate vetting process, where legitimation is but one kind of vetting process among many.

\footnotetext{
${ }^{1}$ It bears noting that I am not, here, focusing on the reasons why traditionally conceived diverse peoples, e.g. racial, ethnic, gender, sexuality, and ability diversity, for example, are not attracted to philosophy as a career path. There are social, political, and class boundaries to deciding upon a career in professional philosophy that should not be overlooked (See, for example, Allen et al. 2008, Sanchez 2011, Gracia 2000). Rather, I am specifically concerned with the environment of professional philosophy for diverse practitioners who have made the choice to pursue philosophy as a career path. Even still, not all people who fall under my definition of diverse practitioner will identify with the problems I highlight. In fact, a great deal of the currently employed under-represented, traditionally conceived diverse philosophers may be perfectly satisfied with the status quo. Unfortunately, their numbers are small. My focus here is on interrogating the conditions that keep this number small.
} 
In what follows, I gesture to a dynamic that is, in part, responsible for the relatively few numbers of diverse peoples in professional philosophy. I highlight that the environment of professional philosophy manifests symptoms of a culture of justification, i.e. a culture that privileges legitimation according to presumed commonly-held, univocally relevant justifying norms, which serves to amplify already existing practices of exceptionalism and senses of incongruence within the profession. Ultimately, I claim that the environment of professional philosophy, particularly in the U.S., bears symptoms of a culture of justification, which creates a difficult working environment for many diverse practitioners. I agree with Allen's assessment that professional philosophy is simply not an attractive setting for many diverse practitioners. ${ }^{2}$ As a means of addressing the downsides of the current culture of justification within professional philosophy, I advocate for a shift in disciplinary culture from a culture of justification to a culture of praxis.

This paper will proceed in five parts. First, I will briefly define the term, 'culture of justification'. Second, I identify symptoms of a culture of justification present in the environment of professional philosophy. Third, I will outline the kind of exceptionalism and incongruence that such a culture amplifies, which serves to create a difficult professional culture for diverse practitioners. Fourth, I offer a beginning step towards an understanding of philosophical engagement that can avoid the pitfalls of a culture of justification. Specifically, I advocate for a shift from a culture of justification to a culture of praxis. Fifth, and finally, I offer a comparative exercise where I show how two disparate positions on philosophical engagement, i.e. Graham Priest's definition of philosophy as critique and Audre Lorde's observations of the limitations of philosophical theorizing, are both manifestations of philosophical engagement according to an understanding of philosophy as a culture of praxis.

\section{WHAT IS A CULTURE OF JUSTIFICATION?}

Gayle Salamon, in her essay, "Justification and Queer Method, or Leaving Philosophy", identifies within professional philosophy the privileging of justification. In fact, she cites the privilege given to justification within professional philosophy as the catalyst for her leaving the field for English. Salamon understands the notion of justification as "making congruent" one's position with acceptable norms (Salamon 2009 , 226). To say that philosophy has a culture of justification, then, is to say that the profession of philosophy requires the practice of making congruent one's own ideas, projects and, in her case, pedagogical choices with some "traditional" conception of philosophical engagement. For Salamon, the activity of making congruent itself is problematic given her conception of queer method and its inherent resistance to harmonizing with status quo conceptions. She writes:

\footnotetext{
${ }^{2}$ Allen, of course, is not alone in holding this position. Sally Haslanger offers a similar statement in her article, "Changing the Ideology and Culture of Philosophy: Not by Reason (Alone)." She writes, "Women, I believe, want a good working environment with mutual respect. And philosophy, mostly, doesn't offer that" (Haslanger 2008, 212).
} 
If justification is concerned with the ordering of beliefs, the reconciliation of one thing with another, the making congruent of different objects or worlds, then queerness as a method would proceed in the opposite way, by supposing a diversion or estrangement from the norm and using that divergence as a source of proliferation and multiplication with the aim of increasing the livability of those lives outside the norm. (Salamon 2009, 229)

Justification as a method requires we attend to prevailing norms and is antithetical, according to Salamon, to queer methods that take estrangement from norms as a point of departure.

A privileging of "justification as a method" refers to a heightened value placed upon processes of legitimation, or identifying congruence between accepted patterns and standards with one's own belief, project, and/or processes, for the sake of positive status. For example, taking justification as an evaluative concept, a standard, internalist theory of justification within epistemology is analogous to Salamon's understanding of "justification as a method" in that it is, itself, a process of legitimation. An internalist theory of epistemic justification, as it is generally conceived, confers positive, epistemic status on a given belief due to whether the given belief is reasonably held (e.g. that the belief accords with one's evidence). In such theories of justification, there is an element of demonstrating the congruence between one's belief and acceptable patterns and standards, or justifying norms, for the sake of positive, epistemic status. Salamon aims to draw attention to a value placed on similar forms of legitimation within the disciplinary culture of professional philosophy as such, where one is asked to demonstrate that one's positions, beliefs, comportment, and/or existence is congruent with some prevailing set of norms for philosophical engagement in order to gain positive status. ${ }^{3}$

Broadly privileging legitimation as an assessment tool for appropriate disciplinary conduct creates a culture of justification within a given discipline. That is to say, within a culture of justification a high value is placed on whether a given paper, for example, includes prima facie congruence with norms of disciplinary engagement, or justifying norms, and/or can inspire a narrative that indicates its congruence with those norms for the sake of positive status. As such, a culture of justification will include at least three components. It will 1) manifest a value for exercises of legitimation, 2) assume the existence of commonly-held, justifying norms that are 3) univocally relevant. That is to say, a disciplinary culture of justification is driven by

\footnotetext{
${ }^{3}$ It bears noting that I see a difference between processes of legitimation and processes of validation. Legitimation takes as a sign of positive status congruence with dominant patterns and standards, where validation refers to evaluative processes more broadly. Validation, here, refers broadly to all processes aimed at establishing the soundness of some belief, process, and/or practice as such. Like legitimation, validation is an evaluative concept, but it is not confined to evaluation according to accepted patterns and standards. In accordance with this distinction, legitimation is a kind of validation insofar as it attempts to establish the soundness or corroborate a practice. Yet, legitimation is not the sole form of validation available. In this paper, I see validation as referring to vetting processes in general and legitimation as referring to a specific vetting process, i.e. justification. I will return to this distinction later.
} 
the creation and/or discovery of papers and/or projects that fall within the purview of a certain set of commonly held, univocally relevant justifying norms. Compliance with these justifying norms, in turn, confers positive status on those papers/projects. It is hard to deny that the environment of professional philosophy currently manifests these three components of a culture of justification. However, if one were tempted to deny this observation, then an interrogation of the question, "How is this paper philosophy?" is warranted. It is through offering a descriptive analysis of this question that the symptoms of a culture of justification can be uncovered within professional philosophy. ${ }^{4}$

\section{SYMPTOMS OF A CULTURE OF JUSTIFICATION IN PROFESSIONAL PHILOSOPHY}

Identifying symptoms of a culture of justification accords with identifying a 1) manifest value placed on legitimation narratives along with a presumption of 2) commonly-held, 3) univocally relevant justifying norms. The question of how a given paper is philosophy is a question that calls for a justificatory account. It is, as Carlos Sanchez might characterize, a question asking for one's philosophical "passport" (Sanchez 2011, 39). As such, the question aims at assessing whether one is doing philosophy according to, presumably, commonly held, univocally relevant norms of conduct. The pervasiveness of the question, i.e. how is this paper philosophy, betrays a value placed on legitimation narratives.

\subsection{PRIVILEGING LEGITIMATION NARRATIVES}

To clarify how the question, "how is this paper philosophy," is a symptom of a culture of justification, I will paint a common scene in professional philosophy contexts. Imagine or recall this scene. After I present this paper at a philosophy conference, the question arises, as it will inevitably arise, "How is this paper philosophy?" The question is undoubtedly a slight, whether the question-asker sees it that way or not. It is both a charge and a challenge. The charge concerns suspicions that the remarks offered are not, in some way, in conformity with relevant justifying norms of philosophical engagement. This charge may find many forms depending on the question-asker. It could manifest as a concern over whether this paper is relevant to historical and current philosophical enterprises; or it could take the form of failing to meet some presumed requisite abstract engagement. No matter the actual charge,

\footnotetext{
${ }^{4}$ The symptoms of a culture of justification I will highlight do not, obviously, establish with absolute certainty that a culture of justification exists in professional philosophy, anymore than symptoms of anemia establish the existence of anemia. However, they do issue a call for further investigation. It is beyond the scope of this paper, to offer a full sociological analysis of professional philosophy. Rather, the aim of this paper is to theorize a possible catalyst for the low numbers of diverse practitioners in philosophy and to encourage future study in this direction. To do this, I need only direct attention to the symptoms of a culture of justification along with the possible problems such symptoms illuminate within professional philosophy.
} 
the challenge remains. The challenge, then, is to "make congruent" or clarify the connection between the remarks offered and some justifying norm of philosophical engagement (however, it is conceived by the question-asker). What is distinctive about the question, how is this paper philosophy, is not that my paper is not prima facie philosophical, but rather the call for legitimation that underwrites the question. That is to say, the answer to the question, "how is this paper philosophy," is assessed according to justifying norms that can confer positive status on my project and, by doing so, show my paper to be "properly" philosophical. This call for legitimation or justification goes beyond whether or not one can produce an adequate account of how one's work is philosophical, which will be contingent upon the justifying norms deemed relevant by the question-asker. It also serves as a symptom that a culture of justification is pervasive within professional philosophy. That is, the frequency of the question, "how is this paper philosophy," betrays a value placed on legitimation narratives. This value is further evidenced by the reality that many professional philosophers find the question, at best, unproblematic and, at worse, routinely appropriate (For accounts that gesture to the pervasiveness of the question, "how is this paper philosophy," see Tiwald 2008, Outlaw and Roth 1997, Nye 1998, Sanchez 2011, Solomon 2001, Walker 2005, Prabhu 2001, Marcano 2010).

A concrete example of the value placed on legitimation narratives in professional philosophy, a symptom of a culture of justification, can be found in Williams Jones' article, "The Legitimacy and Necessity of Black Philosophy". Jones identifies two kinds of legitimation narratives. He claims that one can be asked to justify the "adequacy and significance" of a given philosophical orientation or one can be asked to justify a given philosophical orientation's "right to exist as an appropriate philosophical position" (1977-1978, 149). Diverse practitioners of philosophy are often asked to offer both kinds of justification. There is a rich tradition of such justifications in Africana philosophy, for example. Within an U.S. context, essays by Williams Jones (1977-1978) to Cornell West (1977-1978) to Lucius Outlaw (1997, 1997) exemplify the fact that there are a number of existing attempts to offer narratives of legitimation for philosophy based in the experiences and lives of African-descended peoples. And though the necessity of engaging in narratives of legitimation for Africana philosophy is now being challenged, the external call to justify the existence of Africana philosophy is still strongly felt. ${ }^{5}$

\subsection{COMMONLY HELD, UNIVOCALLY RELEVANT JUSTIFYING NORMS}

Along with a value for narratives of legitimation, held in the question "how is this paper philosophy" is a demand that one make clear how one's paper is congruent with common, univocally relevant justifying norms in order to establish the positive, philosophical status of one's paper. These justifying norms, which often go

\footnotetext{
${ }^{5}$ Africana philosophy is by no means the only kind of philosophy that has been called to legitimate itself. Jorge Gracia, for example, has leveled sustained investigative challenges to the exclusion of Latino/Hispanic philosophers and philosophy within professional philosophy (See, for example, Gracia 2000, Gracia 2008).
} 
unarticulated, are thought to be accepted by all interlocutors and are presumed to be clearly relevant to all philosophical enterprises. The environment afforded by professional philosophy includes an ever-present demand to justify one's philosophical projects and engagements via presumed common, relevant justifying norms. Recall, the presumption of 1) commonly-held, 2) univocally relevant justifying norms are both symptoms of a culture of justification. A brief analysis of a recent narrative of legitimation can aid in identifying this particular symptom in the environment of professional philosophy.

Karsten Struhl's 2010 article in Philosophical Compass, entitled "No (More) Philosophy without Cross-Cultural Philosophy," is a recent example of an attempt to offer a legitimation narrative aimed at establishing the positive status of a different kind of philosophical engagement than is typically accepted within western professional philosophy. Struhl explains, "While this is beginning to change, it is still generally the case that comparative philosophers find themselves on the defensive, as they attempt to insert elements of non-western thinking into an essentially western philosophical curriculum" (2010, 287). Finding himself on the defensive, as a comparative philosopher, Struhl makes an attempt to put practitioners with narrow conceptions of western professional philosophical engagement on the defensive and, as a result, takes up the offensive position as a practitioner of comparative philosophy. He explains, "What I am claiming [in the title] is that the philosophical enterprise cannot adequately fulfill its purpose so long as philosophy remains restrictive to only one tradition" $(2010,287) .{ }^{6}$ Taking philosophical engagement to be defined by "critical and systematic investigations" of fundamental assumptions, Struhl defends that claim that "doing" philosophy requires engagement with crosscultural philosophy for the sake of interrogating fundamental assumptions (2010, 288). Accordingly, Struhl's article ultimately provides an account of the disciplinary significance of comparative philosophy in terms of a, presumably, commonly held norm for philosophical enterprises. In other words, to fulfill the promise of philosophical enterprises, i.e. critical interrogation of our fundamental assumptions, comparative philosophy is necessary. No matter how much this places narrow conceptions of professional philosophy on the defensive, it is a legitimation narrative complete with an appeal to a seemingly common justifying norm.

Though Struhl's offensive position may shift the burden of justification away from comparative philosophers to narrow, professional philosophers, it does so only to the degree that the commonly held justifying norm is taken to be univocally relevant to all philosophical enterprises. That is to say, the shift in the burden of justification can only follow from a mutual and immediate recognition that Struhl has indeed identified a commonly held and univocally binding justifying norm. In making the claim that comparative philosophers are particularly well suited to philosophize in accordance with the norm of interrogating fundamental assumptions, he issues a call

${ }^{6}$ It bears noting that this claim mirrors William Jones' claim in his article, "The Necessity and Legitimacy of Black Philosophy" and the understanding of philosophical practice held in Struhl's article is remarkably similar to Alain Locke's understanding of philosophy as philosophies of life (See 1977-1978, Locke 1991). 
for legitimation aimed at philosophers who would challenge the philosophical merit of comparative philosophy given its optimal compliance with the justifying norm in question. If the performance of Struhl's article is to succeed at all, it does so to the degree that the norm he identifies is actually prima facie relevant to all philosophical enterprises. If the norm of interrogating our fundamental assumptions does not have this kind of all-encompassing relevance, then Struhl's attempt to put a certain class of philosopher on the defensive is futile. One need only respond to Struhl by rejecting the justifying norm identified. This does not figure into Struhl's analysis because it is often presumed by many professional philosophers that one of philosophy's primary roles $i s$ to systematically interrogate fundamental assumptions.

Regardless of whether Struhl has identified a genuine, commonly held, univocally relevant justifying norm, he is certainly relying upon the existence of such norms for the success of his account. Struhl's account, though a very good defense of comparative philosophy, does not challenge the call for legitimation narratives as such. It is, rather, a good example of two symptoms of a culture of justification present in the environment of professional philosophy, i.e. the presumption of 1) commonly held, 2) univocally relevant justifying norms.

\section{ON GRISLY GROUND: DIVERSE PRACTITIONERS AND THE ENVIRONMENT OF PROFESSIONAL PHILOSOPHY}

The environment of professional philosophy, which contains symptoms of a culture of justification, is often rendered inhospitable for diverse practitioners due to "silent exclusions" (Marcano 2010, 54). In a culture of justification, historical, unwarranted exclusions come to inform the very justifying norms relied upon for legitimation. That is, the presumption of commonly held, univocally relevant justifying norms, when informed by unwarranted exclusions, creates means of validation incapable of tracking those exclusions. In fact, those exclusions can easily become seen as "reasonable" via disciplinary practice itself. In this section, I will highlight two kinds of exclusions that are hard to track in a culture manifesting the three symptoms of a culture of justification. They are exclusion via exceptionalism and exclusion via a sense of incongruence. Where exclusion via a sense of incongruence is a direct result of the fact that there are few, if any, commonly held, univocally relevant justifying norms, exclusion via exceptionalism gestures to the point where disciplinary cultures simply fail to accurately assess legitimation.

\subsection{EXCLUSION VIA EXCEPTIONALISM}

Sandra Harding offers a definition of exceptionalism in her introduction to The Postcolonial Science and Technology Studies Reader. She writes:

Exceptionalism assumes that the West alone is capable of accurate understandings of the regularities of nature and social relations and their underlying causal tendencies. There is one world, and it has a single internal order. One and only one science is capable of 
understanding that order. And one and only one society is capable of producing that science: our Western society!” (Harding 2011, 6).

Though Harding is speaking specifically of scientific explorations, the definition is relevant here. Exceptionalism involves the unfounded, exclusion of large bodies of investigation based upon the privileging of one group (or set of groups) and their investigations over others. Excluded groups might actually meet many of the demands imposed by operative, justifying norms. However, they are still excluded due to historical privileging of investigative enterprises produced by privileged populations. ${ }^{7}$ The exclusions of non-western philosophy in American professional philosophy, for example, can be seen according to a kind of exceptionalism.

Non-western philosophy, as has been pointed out repeatedly, can be legitimated according to several prevailing, justifying norms for philosophical engagement. In his article, "Philosophy in an Age of Global Encounter," Joseph Prabhu writes:

If philosophy consists in systematic attempts to address fundamental questions about the nature of reality, the nature of methods of knowledge, the basis of moral aesthetic values and judgments, the self, and the meaning and goal of religion, then there is abundant philosophy in Indian, Chinese, and Islamic thought. (I cannot speak of African philosophy because of my own ignorance, but I would presume that it too embodies systematic reflection about the nature of things). $(2001,30)$

After citing several productive exchanges between western philosophers and nonwestern philosophers, like the exchanges between Michael Dummett and Bimal Matilal along with J.N. Mahanty's fruitful engagement with the work of Gottlieb Frege and Edmund Husserl, Prabhu concludes, "thus it cannot be on philosophical grounds that non-western philosophy is so neglected in American universities at present" (2001, 30). As a result, Prabhu concludes that something else is clearly afoot. Here we see recognition of a kind of exceptionalism.

What Prabhu draws attention to is the fact that not everyone has equal access to justifying norms in an American professional philosophy context. Exceptionalism within professional philosophy works to not only refuse some access to justifying norms, but to also exempt others from being subject to certain prevailing justifying norms. For example, there are black philosophers with positions that hold marginal anti-white sentiments that some disregarded as racist (e.g. Alexander Crummell), while white American or European philosophers with similar anti-black sentiments

\footnotetext{
7 'Privilege' is a relative term. According to Peggy McIntosh, systemic privileging refers to "unearned power conferred systematically" (McIntosh 2008, 66). Though many African Americans voices, for example, may be privileged over many Haitian voices in terms of their ability to impact U.S. social spheres, they are both underprivileged with respect to many White voices. In turn, wealthy White voices are often privileged over poor White voices. The term 'privilege', in this analysis, refers to broader structure of evaluation, where entire legitimation structures are tainted with the oppressive privileging of certain social identities and social, investigative practices in the form of "unearned power conferred systematically". For more thorough accounts of privilege see McIntosh 2008, Bailey 1998.
} 
that are forgiven as products of their time (e.g. G.W.F. Hegel). Clearly there are overarching social and political considerations that inform the decisions on who counts as an exception to justifying norms that are not actually reflected in the justifying norms themselves. Because exceptionalism is largely determined by social and political structures of empowerment and disempowerment, it cannot be addressed with adding more justifying norms. In the case of exclusion via exceptionalism, justifying norms, themselves, are not the problems. The people applying them are the problem. A culture of justification, or a culture that manifests the three main symptoms of a culture of justification, has few resources for addressing the misapplication of justifying norms. Privileging legitimation narratives and presuming the existence of commonly-held, univocally relevant justifying norms does not assure there is also a value placed on the appropriate use of those norms. Rather, privileging legitimation narratives assures that most disciplinary practitioners feel as if they are judge and jury over "appropriate" professional conduct and production, while never recognizing the demand to acknowledge the ways prevalent social and political structures of empowerment and disempowerment influence their judgment. ${ }^{8}$

\subsection{EXCLUSION VIA A SENSE OF INCONGRUENCE}

The second form of exclusion is exclusion via a sense of incongruence. Whereas exceptionalism pertains largely to the uneven persuasive power of justifying norms, incongruence refers to unequal acceptance of justifying norms. That is, many diverse practitioners do not accept as valid current, dominate justifying norms within professional philosophy. In this case, a sense of incongruence with current justifying norms hinders one's ability to argue for the positive philosophical status of one's projects. This can be seen in Gayle Salamon's reaction to the call to legitimate her pedagogical choice of relying upon queer theory and methods in her philosophy classes. This call put her in the position of accepting, against her will, the norm of justifying as such, which runs counter to her own personal, political, and theoretical leanings (Salamon 2009). She is not alone in experiencing the sense of incongruence she describes. Jacqueline Scott, when asked to discuss her experience as a black woman, professional philosopher, describes the sense of not fully accepting or fulfilling philosophical expectations. She labels this sense of incongruence, "dissonance" (Allen et al. 2008, 185).

\footnotetext{
${ }^{8}$ Some may say that if justifying norms are not the problem of exceptionalism per se, then what is needed are better applications of prevailing justifying norms not, as I will argue later, an alteration of roles assigned justifying norms altogether. It is important to understand the degree to which exceptionalism is largely unconscious. In their respective articles, Virginia Valian and Sally Haslanger, identify the impact of gender schemas on evaluations of philosophical performances where women are routinely judged more harshly than their male counterparts and made subject to exceptionalism due to being women philosophers (Valian 2005, Haslanger 2008). When one's very judgment manifests tendencies towards exceptionalism, this is not an easy pattern to break. It is more reasonable to foster a climate that neutralizes such biases than to harbor hope for the elimination of those biases.
} 
Indeed, Salamon and Scott are not the only diverse practitioners of philosophy who have confessed to a sense of incongruence with respect to justifying norms for "proper" philosophical conduct and investigation. A great deal of feminist philosophy began as a rejection of some set of justifying norms within professional philosophy. ${ }^{9}$ Still others feel a sense of incongruence with professional philosophy's expectation of a panoramic view and the, often misunderstood, particularity attached to "minority" social identities. Donna-Dale Marcano, in her article, "The Difference that Difference Makes: Black Feminism and Philosophy," gives an account of the reality that a black woman philosopher who takes as her point of theoretical departure the lives and experiences of black women is often conceived as doing work so particular "that philosophy resists its presence" $(2010,53)$. Marcano, of course, does not accept the expectation that philosophical theorizing begins from the broadest possible vantage point. ${ }^{10}$ The rejection of this justifying norm ushers in a sense of incongruence between her philosophical projects and professional philosophical expectations, in her estimation.

In a similar fashion, Carlos Sanchez, in his article, "Philosophy and PostImmigrant Fear," highlights the fact that the demand for disembodied philosophizing as a marker for what counts as philosophy is one of the ways professional philosophy is inhospitable to "Hispanic philosophers" and "Hispanic philosophy". He writes, many professional philosophers believe "if a thinking situates itself, embodies itself, or historicizes itself, then it is not profound, and worse, not philosophy" (Sanchez 2011, 40). The value of disembodied, a-historical philosophical engagement is clearly not a value shared by either Sanchez or Marcano for converging and diverging reasons. These are but a few examples of the myriad ways a sense of incongruence plagues many diverse practitioners within professional philosophy. No matter its origin, I suggest that part of what forms these senses of incongruence is a failure to accept a justifying norm or a given set of justifying norms prevalent within professional philosophy context.

\subsection{EXCLUSION AND LEGITIMATION NARRATIVES}

The presence of exceptionalism and incongruence among professional philosophers points to the difficulty of sustaining diverse practitioners. If positive, philosophical status follows from prima facie legitimation and adequate narratives of legitimacy, and these, in turn, rest on dominant, justifying norms, then being barred access to relevant justifying norms (via exceptionalism) or failing to accept justifying norm according to which one is assessed (via incongruence) demonstrates the ways legitimation represents an impossible goal. Without access to typical justifying norms, the goal of justification is futile. Similarly, if one's work reflects a rejection of

\footnotetext{
${ }^{9}$ Take, for example, some feminist ethics rejections of "theoretical-juridical models" for moral theory (See Jaggar 2000, Walker 1992) or some feminist epistemology rejections of neutral-subject assumptions within theories of knowledge (See Code 1993, Code 1981).

${ }^{10}$ She shares this orientation with other Black philosophers. See, for example, Outlaw Jr. 1996, Locke 1991, Jones 1977-1978, Outlaw Jr. and Roth 1997, Harris 1997.
} 
the justifying norms being used as criteria for assessment, then it seems similarly futile to pursue legitimation. If positive, professional philosophical status rests on the fair application of justifying norms and the uniform acceptance of those norms, then many diverse practitioners can expect to fail adequacy tests by rote.

Some may object that the picture I have painted here is too grim. They may point out that I have made an error in casting the justifying norms within professional philosophy as a set of static, easily identifiable criteria. They may agree with Andrea Nye, in her review article, " 'It's Not Philosophy'," that

Even when ratified by a version of intellectual history that covers up personal or political sources of philosophical wisdom or that privileges science as the only source of knowledge, philosophy's parameters remain unstable. That the very insistence on what is 'real' or 'hardcore' philosophy against what is 'only' poetry, sociology, personal memoir, or politics itself renews the possibility of yet another philosophical reconstitution" (1998, 108).

The hope here is that in a culture that manifests the three symptoms of a culture of justification, justifying norms are continuously destabilized and revised via the very demand for narratives of legitimation. There can be little doubt that justifying norms for philosophical engagement change over time. In fact, it may be true, as Stan Godlovitch argues, in his article, "What Philosophy Might be About: Some Sociophilosophical Speculations," that philosophy is simply a discipline that is constantly reconceptualizing its own past given shifts in socio-political climates $(2000,17)$. However, one has to examine closely who has the burden of destabilizing norms at any given time and whether this is a worthy activity for the targeted populations. Diverse practitioners may disproportionally shoulder it. I believe the burden of shifting the application and content of justifying norms influenced Anita Allen to pose the question whether professional philosophy provides a good working environment for black women. It is, I presume, part of the burden that Gayle Salamon refused to shoulder, which made English a more desirable career choice. And it is absolutely the burden I would never wish upon my younger sister.

The burden of shifting justifying norms within a professional environment that manifests symptoms of a culture of justification involves sacrificing one's labor and energies towards providing a catalyst for change via numerous legitimating narratives aimed at gaining positive status for oneself as a philosopher and one's projects as philosophical. Let me make the strong statement that shouldering this burden and the set of experiences one exposes oneself to is not a livable option for many would-be diverse practitioners of philosophy and the small numbers of under-represented populations within professional philosophy attest to this observation. There are, to speak euphemistically, better working environments for diverse practitioners, which may not be perfect, but may certainly count as providing more opportunities for the success of one's own life and projects than professional philosophy. Perhaps Sally Haslanger says it best: 
I don't think we need to scratch our heads and wonder what on earth is going on that keeps women [for example] out of philosophy. In my experience, it is very hard to find a place in philosophy that isn't actively hostile toward women and minorities, or at least assumes that a successful philosopher should look and act like a (traditional, white) man. And most women and minorities who are sufficiently qualified to get into graduate school in philosophy have choices. They don't have to put up with this mistreatment. (Haslanger 2008, 212, italics in the original) ${ }^{11}$

It is the realization that black women who are qualified to pursue philosophy have other options that leads Allen to pose her challenge to assess the environment of philosophy for the possibilities it holds for one's own projects and quality of life. ${ }^{12}$ It is also quite possibly why Allen states of her shift in careers from philosophy to law, "I did not like law as much as philosophy, but I was much, much happier as a law professor than as a philosophy professor. I hit the ground running" $(2008,172)$. Hitting the ground running is unlikely for many diverse practitioners within a professional philosophy environment where a disproportionate burden of shifting justifying norms is placed on those very practitioners.

\section{A PROPOSAL: TOWARDS A CULTURE OF PRAXIS}

Problems of exceptionalism and incongruence become significant in a professional environment that manifests the three main symptoms of a culture of justification. That is to say, no one can absolutely control unwarranted exceptionalism, nor can (nor should) one control the myriad senses of incongruence among diverse practitioners. So part of making professional philosophy a more inclusive discipline will include reducing the effect of exceptionalism and recognizing the creative capacity of senses of incongruence. Hence, we need to work towards a disciplinary culture that not only lessens the effect of exceptionalism, but can also create an environment where incongruence becomes a site of creativity for ever-expanding ways of doing professional philosophy. I propose that a step towards a more inclusive environment within professional philosophy can start with a shift away from values held in a culture of justification to values held in a culture of praxis. A culture of praxis might

\footnotetext{
${ }^{11}$ Haslanger's quote speaks not only to professional expectations (i.e. justifying norms), but also to interpersonal dynamics (e.g. blatant sexism and/or racism). I do not specifically address interpersonal dynamics here. In a professional environment, I understand interpersonal dynamics to be curtailed, to the degree they can be curtailed, by the prevalent, professional culture. The existence of racism and sexism in professional philosophy does not, by itself, explain the dismal numbers of women, racial and ethnic minorities within professional philosophy. It is unusual, within a U.S. context, to have a working environment free of racism and sexism. And, yet, there are still working environments more friendly to women and people of color in the U.S., even where racism and sexism remain pervasive. In short, poor social and interpersonal dynamics alone cannot account for the low numbers of black women in professional philosophy. Hence, here I focus on one of the ways poor, interpersonal dynamics are exacerbated, i.e. professional culture.

${ }^{12}$ Certainly, this is part of the challenge Allen issued to the black women present at the $2^{\text {nd }}$ Collegium of Black Women Philosophers in 2009.
} 
provide a disciplinary culture that can increase livable options within professional philosophy. A culture of praxis, I propose, has at least the following two components:

(1) Value placed on seeking issues and circumstances pertinent to our living, where one maintains a healthy appreciation for the differing issues that will emerge as pertinent among different populations and

(2) Recognition and encouragement of multiple canons and multiple ways of understanding disciplinary validation.

In what follows I will develop briefly each of these components.

The idea that professional philosophy should come to place value on inquiries into issues and circumstances present in our historical time is not a new idea. Philip Kitcher has recently called for such a shift in his 2011 article, "Philosophy inside Out." In his "plea for philosophical redirection," Kitcher aligns himself with John Dewy in his call for the realization that contemporary philosophical investigations, at any given time, begin with "philosophical problems [that] emerge from situations in which people - many people, not just an elite class - find themselves" (Kitcher 2011, 250). A culture of praxis, on my account, would value investigations that contribute to old, new, and emerging discussions, problems, and/or investigations. As Kitcher explains, value would be placed on everything from "the state of inquiry, to the state of a variety of social practices, and to the felt needs of individual people to make sense of the world and their place in it" (Kitcher 2011, 254). One will no longer be asked to justify one's projects according to some set of justifying norms, but rather one does need to identify a point of contribution within contemporary philosophy, outside of contemporary philosophy, and/or in our surrounding worlds.

One can quickly object to the proposal to value contributory projects, however they are formed, with offering the observation that this value operates as simply another method of justification. Recall the distinction I drew between legitimation and validation. Legitimation requires some set of justifying norms that are commonly held and univocally relevant. Validation, on the other hand, refers more broadly to evaluations of soundness as such. It may be difficult and unwise, to say the least, to eliminate all forms of validation. However, legitimation is but one form of validation. If, in a culture of praxis, validation is determined according to contribution, then it need not be understood according to a legitimation narrative. In fact, it is entirely possible that the call to identify one's contribution not only contextualizes validation in a way commonly-held, univocally relevant justifying norms does not, but also distributes the burden of validation more evenly. Everyone's projects must contribute. And all projects will be seen as situated in historical questions, contemporary needs, and/or new or emerging investigations. Wherever one turns their energies, one must contribute. ${ }^{13}$ In a culture of praxis, justifying norms that aim to shape topics and or

\footnotetext{
${ }^{13}$ It is important to note that "contribute" is used very broadly. It is reasonable that some professional philosophers who might want to decipher elusive knowledge problems as contributing to a discourse on such matters. However, it is likewise true, that philosophers concerned with race, class, gender, and immigration issues, for example, can contribute to these discourses.
} 
character of all philosophical investigation no longer operate to delimit how one contributes. This shift alone can aid in producing an environment where senses of incongruence become the sites of new investigations, methods, and livable options, as Salamon suggests (2009).

It is true that valuing the contribution of one's works as part of a culture of praxis does not move us entirely away from methods of justification. In fact, it is very likely that a proliferation of investigations, inquiries, and questions will create a proliferation of canonical works and criteria that will be used as justifying norms. These norms, however, will not be generalizable in the way justifying norms appear to be today. Also, philosophical engagement will not be determined solely by these justifying norms. Justifying norms will become an important part of philosophical criticism, where judgments of good and bad philosophy are made, and not judgments concerning the philosophical nature of those endeavors. One does not call a bad short story a collection of words, except in a tongue and check fashion, because it is a bad short story. Accordingly, philosophy can be deemed poor philosophy without it ceasing to be philosophy.

What the initial valuing of "live" issues and actual contribution ensures, however, is an encouragement of multiple philosophical canons and a fragmentation of justifying norms (including new and developing justifying norms). The philosophical work produced and the questions asked in a culture of praxis will not always be compatible or capable of consolidation due to the divergent inquires and experiences that inform them. This would force recognition of the fragmentary nature of professional philosophy, where canons and justifying norms appear more relevant in some inquiries than others, which is very similar to how philosophical engagement actually operates today. ${ }^{14}$ What is being proposed is, as Kitcher coins, a "philosophical redirection" (2011), where the current activities in philosophy are evaluated differently (See also Outlaw 1996). Again, legitimating narratives may be introduced, but would function differently. Justification according to a supposedly monolithic set of justifying norms would no longer be relevant. Rather, smaller, reflexive validation mechanisms can emerge in accordance with the inquiries and questions under investigation. An appreciation of the smaller canons that emerge lessens the need to lay claim to some overarching set of canonical texts and or questions in order to claim positive, professional philosophical status.

Accordingly, a culture of praxis, where projects are not predetermined and canons are multiple, lessens the effect of exceptionalism. Let me be clear, it may not lessen the existence of exceptionalism, but it allows for the growth of communities of scholars to exist relatively free of the demands made by those who would practice such exceptionalism. That is to say, relatively little time need be spent defending

\footnotetext{
${ }^{14}$ Some may say that the inability for philosophical insights to be consolidated, speaks to how this proposal is unrealistic. One might even attempt to make an analogy between a natural science, like microbiology, and philosophy, stating that because a culture of praxis appears untenable for microbiology, it should also be untenable for philosophy. This is a false analogy due to the presumed existence of natural laws, where there is no unproblematic presumption of equivalent philosophical laws.
} 
one's project to a practitioner of philosophy who will never be convinced of the value of one's work. Rather, energies can be diverted toward making contributions within one's communities. Some may observe that this kind of focus already happens among diverse practitioners. This is true, but it happens as part of the "periphery" of philosophy due to a failure to gain easily recognizable, positive, philosophical status. In a culture of praxis, the concept of periphery and mainstream would make little sense and value will be placed on identified points of contribution. This is mainly due to the fact that, in a culture of praxis, what creates philosophical communities is a concern for contributions made according to one's interests and community involvement, rather than a shared set of justifying norms.

There are at least two objections to my proposal to move to a culture of praxis. The first concerns a presumed inability to preserve the idea that professional philosophy has its own distinct disciplinary specialization. The idea is just this: if justifying norms that govern what counts as philosophy drop away, then what makes philosophy distinctive also drops away. This objection seems to follow from the idea that philosophy and philosophizing are not a widespread, human activity. It contains the assumption that there is something special about philosophizing that is in the purview of professional philosophy alone. This is a form of exceptionalism insofar as it unacceptably rarifies professional philosophical engagement, i.e. it privileges the output of one population over another. Let me offer an analogy to clarify this point. There are creative writers all over the world. Most creative writers will never be able to sustain themselves purely on creative writing, but they write nonetheless. Some of the factors that thwart some creative writers' hopes of fame and financial support concern social, political and geographical privileges, differences in talent, and trends in criticism. These factors, however, do not determine the existence or non-existence of creative writers and creative writing. The inevitable widening of philosophical engagement that would follow understanding such engagement according to contribution does not lessen the activity and production of philosophy, any more than an extraordinarily wide conception of creative writing eliminates the activity and production of creative writing. Creative writing is still a widespread human activity; in like fashion, philosophy is a widespread human activity. ${ }^{15}$

The second objection, gestured to earlier, concerns whether a shift to a culture of praxis is too extreme. If the problem is, for example, poor application of justifying norms and poor justifying norms, why not require better application of justifying norms and better justifying norms? Within a disciplinary culture that manifests symptoms of a culture of justification, the revision of justifying norms tends to fall disproportionally upon diverse practitioners. This is, to be plain, unacceptable. I take a culture of praxis to be calling for better applications of justifying norms and better justifying norms in a way that also distributes the burden of making these changes. If justifying norms and legitimation are difficult to eliminate as a form of validation,

\footnotetext{
${ }^{15}$ Some identify the demise of philosophy in higher education as primarily resulting from attempting to rarify philosophy. See, for example, Lee McIntyre's recent opinion essay in The Chronicle Review, entitled "Making Philosophy Matter - or Else" (2011).
} 
then they need to be placed in perspective. They are not always commonly held, nor are they ever univocally relevant. A professional disciplinary culture needs to make room for this reality. And a culture of praxis, on my account, can account for fragmentary, diverse justifying norms by displacing all-encompassing justifying norms for contextual assessments of contribution. In what follows, I will give an example of how a culture of praxis can work to neutralize, to a degree, exceptionalism and aid in creating a space where senses of incongruence can become sites of creative philosophical engagement.

\section{A COMPARATIVE EXERCISE: TESTING THE TWO COMPONENTS IN A CULTURE OF PRAXIS}

In order to gain a fuller understanding of the culture of praxis in professional philosophy, I will briefly describe two understandings of philosophy, i.e. Graham Priest's definition of philosophy as critique and Audre Lorde's observations of the limitations of philosophical theorizing. I do this to show how both accounts can be seen as philosophical engagement in accordance with the two components of a culture of praxis.

\subsection{GRAHAM PRIEST AND PHILOSOPHY AS CRITIQUE}

After disagreeing with Wittgensteinian and Rortian understandings of philosophy, Graham Priest, in his 2006 article, "What is Philosophy?" offers a conception of philosophy that he labels, "philosophy as critique" (200). On Priest's view, philosophy entails a negative and positive project. It is has both critical and constructive arms. Priest writes, "Learning philosophy is not simply learning a bunch of facts; it is learning how critically to evaluate people's ideas" (2006, 201). Though criticism may be said to flourish in any field, it holds a distinct place in philosophy. "What distinguishes the role of criticism in philosophy is," Priest writes, "precisely that there is nothing that may not be challenged" (Priest 2006, 202). So not only is philosophy defined by criticism, that orientation is itself "unbridled" (Priest 2006, 201). Hence, for Priest, "philosophy is precisely that intellectual inquiry in which anything is open to critical challenge and scrutiny" (2006, 202).

The critique-centered nature of philosophy serves to produce three features, on Priest's account. Philosophy is 1) subversive, 2) unsettling, and 3) of universal import (Priest 2006, 202-203). Presumably, because philosophers are prepared to challenge everyday common beliefs, philosophy is subversive. And this subversiveness is unsettling to the new student of philosophy, according to Priest. The claim concerning the "universal import" of philosophy, however, follows from nature and value of criticism. Priest writes:

Philosophy is of universal import. Concerning any field of inquiry, one may ask pertinent philosophical questions. One does this when one challenges things that the inquiry itself takes for granted. This is exactly what the philosopher has a license to do. $(2006,203)$ 
Here, asking questions is synonymous with making challenges. It is the making of challenges that shows philosophy's universal import. There is no assumption a philosopher cannot question and no position a philosopher cannot challenge. Priest will go on to suggest that if the common practice of attacking positions put forward by philosophers at professional conferences is any indication, then his interpretation of philosophy is correct. "Criticism," Priest adds "is the life-blood of the discipline" (2006, 203). Philosophy, then, holds a critique-centered spirit that takes as its object anything and everything, and, as such, is a discipline with universal import.

The critique aspect of philosophy is the negative element of philosophizing. Priest also adds a positive element of philosophizing realizing that conceiving of philosophy as merely combative criticism is probably not a "terribly attractive picture" (2006, 203). So he adds the observation that "philosophy is a highly constructive enterprise. Philosophers are responsible for creating many new ideas, systems of thought, pictures of the world and its features" $(2006,203)$. It becomes very apparent that Priest holds the constructive side of philosophy, i.e. the creation of new ideas, to be the harder and the more rewarding side of philosophy. Yet, upon a careful reading, even the constructivist side is done for the sake of criticism. Priest explains that it is easy to be a "knocker" or a person who only knows how to critique the positions of others. It is an altogether more difficult endeavor to offer criticism that is supported with a "rival theory" (Priest 2006, 204). "Criticism," Priest explains, "is...most powerful only when it has the backing of some rival theory" $(2006,204)$. The new ideas in philosophy arise out of responses to and criticisms of old ideas. What underwrites this understanding of philosophy and its alleged universal import is the so-called intrinsic value of finding problems (via criticism), then finding solutions to problems (via rival theories).

This understanding of philosophy is not unusual. It is actually rather common. It is a definition of intellectual activity that many black feminists find less than fruitful, however. In what follows, I will articulate Audre Lorde's observations concerning the limitations of this kind of theorizing, where Lorde's tacit understanding of theorizing is very similar to Priest's definition of philosophy. Hence, if philosophy is understood according to Priest's conception of philosophy as critique, Lorde offers an account of serious limitations for philosophical theorizing. Again, the challenge here is to show how a culture of praxis can accommodate both Priest's conception of philosophy and Lorde's observations of its limitations.

\subsection{AUDRE LORDE - SURVIVAL IS NOT AN ACADEMIC SKILL}

Lorde juxtaposes poetry, which is driven by experience and feelings, on her account, with theoretical enterprises, which are driven by conceptual thinking and criticism. She establishes that one of the values of poetry is the ability to render merely theoretical observations relevant to actual living. Though Lorde offers an interesting defense of the necessity of poetry in her work, what is of interest here are the limitations she sees in philosophical theorizing that makes it a "handmaiden" to 
poetry $(1984,56)$. For Lorde, the limitations of philosophical theorizing concern a commitment to the rationality-from-nowhere ideal and a commitment to the view that the meaning of living is solving problems.

\subsubsection{RATIONALITY-FROM-NOWHERE}

In a 1979 interview with Adrienne Rich, Rich questions Lorde about a set of positions she puts forth in her 1977 article, "Poetry is not a Luxury". Lorde's position reads, "The white fathers told us: I think, therefore I am. The Black mother within each of us - the poet - whispers in our dreams: I feel, therefore I can be free" (Lorde 1984, 38). Rich asks Lorde to respond to the criticism that she is, here, simply restating an old set of stereotypes of "the rational white male and the emotional dark female" (Lorde 1984, 100). Lorde's response is fascinating. One would expect her to defend herself against the charge that she is espousing the belief that only white males are properly rational and only "dark females" are properly emotional. Instead she responds by dissolving the critique:

I have heard that accusation, that I'm contributing to the stereotype, that I'm saying the province of intelligence and rationality belongs to the white male. But if you're traveling a road that begins nowhere and ends nowhere, the ownership of the road is meaningless. If you have no land out of which the road comes, no place that road goes to, geographically, no goal, then the existence of that road is totally meaningless. Leaving rationality to white men is like leaving him a piece of that road that begins nowhere and ends nowhere. $(1984,100)$

According to Lorde, there is something meaningless about the concept of Rationality. The understanding of the human practice of exercising reason held in Rationality, for Lorde, has no origin, no destination, and no goal. It does not have a specifiable locale and as such it has no use. Now, is she saying that all rationality is meaningless, in general? No, because Lorde will go onto explain:

Rationality is not unnecessary...it serves feeling. It serves to get from this place to that place. But if you don't honor those places, then the road is meaningless. Too often, that's what happens with the worship of rationality and that circular, academic, analytic thinking. $(1984,100)$

Lorde appears to challenge whether the concept of Rationality is useful given that it is a concept of a human practice, not the practice of being rational or exercising reason. The practice of rationality always has a location. There is a where-from and a whereto for every attempt to be rational. Honoring the place and space of given instances of reason is what affords rationality meaning. Hence, attempts to render reason abstract, without appeal to space and place are, on Lorde's account, meaningless. So an assumption of ownership over such a concept amounts to an inconsequential claim.

\subsubsection{LIVING AS A PROBLEM TO BE SOLVED}


A way to defend the value of concepts of human practice, like Rationality, could follow from understanding conceptual thinking as a way to address contemporary problems. By addressing problems in the world, philosophy can help to guide human behavior. For Lorde, this response is contingent on a certain approach to the world and living. It conceives of living as if it presented itself as a set of problems to be solved. Lorde, on my reading, observes limitations to this particular worldview. She writes:

When we view our living in the european mode, only as problems to be solved, we rely solely upon our ideas to make us free, for these were what the white fathers told us were precious. But as we come more into touch with our own ancient and original noneuropean view of living as a situation to be experienced and interacted with, we learned more and more to cherish our feelings, and to respect those hidden and deep sources of our power from whence true knowledge and, therefore, lasting action comes. (Lorde 1984, 37)

Lorde, here, sees a clear connection between a particular worldview and the reliance upon ideas. Regardless of whether her designation of "european" and "non-european" is correct, taking living "as a problem to be solved" leads one to both believe in and rely upon ideas in a certain way. It would behoove us to try to articulate what a problem/solution conception of living might entail. There are at least three commitments. The first would concern valuing the activity of discovering problems. The second would concern placing a value on analyzing these problems in order to determine possible solutions. And the third commitment would concern articulating solutions to the problems. It is not clear where, according to a problem/solution approach to living and its three commitments, one need ever act upon a solution. Uncovering ideas alone is presumed to have revolutionary force. All that is needed to change the world is to think of a solution. It is not clear, for Lorde, how this orientation for living, the creation of ideas in the form of problems and/or solutions, can ever make demands upon our actions by itself. The question here is the following: how precisely will discovering, determining, and articulating problems and/or solutions make demands upon our actions?

Lorde, here, seems to be suspicious of how ideas and conceptual thinking can make demands on our actions. More precisely, because conceptual thinking can and does make errors, the process of finding problems and solutions is infinitely regressive. For example, the above question of 'How will discovering, determining, and articulating problems/solutions make demands on our actions,' if taken as a problem that needs to be solved, will produce answers which themselves are problems to be solved. One can lose herself/himself in the process of finding problems and offering solutions. Reframed in the terms of Graham Priest's conception of philosophy as critique outlined earlier, one can lose herself/himself in the infinite regress of criticism and rival theories without ever acting in accordance with a single idea. In fact, the problem/solution model, or the criticism/rival theory model, by itself, may be a means of suspending action indefinitely. As a result, Lorde 
demonstrates that relying solely on ideas and concepts does not make demands on our actions, but rather must be combined with some other form of human activity, i.e. poetry, that translates theory into action (Lorde 1984, Lorde 2009). As a result, she is not outright rejecting philosophical thinking, as she understands it, but rather observing its limitations.

Philosophy, when taken as criticism and rival theories, is implicated by Lorde's observations concerning problem/solutions models. A problem/solution orientation underwrites a criticism and rival theory conception of philosophy. In what follows, I will not attempt to defend Graham Priest's idea of philosophy as critique or Audre Lorde's proposed limitations to such an activity, though both positions, I believe, can be defended for different reasons in very different contexts. Instead, I aim to show how both Priest's definition of philosophy and Lorde's observed limitations for philosophical theorizing can be accommodated with the two components contained in a culture of praxis.

\subsection{HOW DO THEY PRACTICE PHILOSOPHY?}

Neither Priest's, nor Lorde's remarks offered here are original. However, I chose Priest's conception of philosophy as critique and Lorde's observed limitations of philosophical theorizing very deliberately. Neither conception is particularly easy to reconcile with the components I identify as present within a culture of praxis. Recall, the first component is value placed on identifying and pursuing "live" concerns and/or questions and the second component concerns recognition of the proliferation of canons and justifying norms. On my reading of Lorde, the emphasis on concerns and/or questions in the first value may appear to render Lorde non-philosophical. And, on the surface, Priest's conception of philosophy looks largely irrelevant in this discussion as a relic of a culture of justification. ${ }^{16}$ However, there are several features of Priest's and Lorde's respective observations that make them well suited to exemplify how a culture of praxis might work.

\subsubsection{COMPONENT 1: VALUE PLACED ON CONTRIBUTING TO "LIVE" CONCERNS}

Again, the first component of a culture of praxis is a value placed on seeking issues and circumstances pertinent to our living. Lorde, as was briefly mentioned, rejects the orientation that living presents itself as a set of problem to be solved. As such, the idea that philosophy is primarily composed of the identification of concerns and/or questions to be investigated and engaged is not an orientation to which Lorde might readily subscribe. However, it is not clear that Lorde's desire to move away from a problem/solution worldview renders seeking pertinent issues and circumstances irrelevant. In fact, she explains that both philosophical theorizing and something like

\footnotetext{
${ }^{16}$ See Dotson 2011, Moulton 1996, for accounts that observe the ways criticism within philosophy shores up a culture of justification.
} 
poetry are necessary for survival (Lorde 1984, 37). However, privileging philosophical theorizing without a medium that situates that theorizing so as to produce viable action is futile. As such, Lorde, in observing limitations to the brute search for problems and solutions, is offering an alternative methodology for pursuing applicable insights. What counts as theorizing that contributes to "live" problems, according to Lorde's understanding of the limitations of problem/solution philosophizing, would shift significantly. Accordingly, her conception of philosophical writing would shift significantly. Literature, poetry, autobiography would count as viable sources for philosophical engagement.

It is clear that what philosophy would look like, for Lorde, would be very different than what philosophy would look like for Priest. This is primarily because what counts as a contribution would look very differently depending upon the methodological commitments one holds, i.e. either Lorde's conception or Priest's conception. This observation alone would not render Lorde's approach lacking in positive, philosophical status. Such an assessment would be irrelevant. ${ }^{17}$ In this case, we can see how a culture of praxis can aid in proliferating the kinds of methodologies one relies upon and the texts included in one's canon. In other words, Lorde's work can increase the livable options for philosophical practitioners within professional philosophy, if it is not made to answer to, let us say, the justifying norms that follow from Priest's account of philosophy as critique.

Priest's account is far easier to reconcile with the value of seeking "live" questions. Priest, at no point in his article, specifies a single body of relevant questions. In fact, for Priest there is nothing that cannot be questioned. Hence, the creation of a singular body of appropriate problems and/or questions seems to be antithetical to his approach. And even if some should feel the need to construct a set of "appropriately" philosophical questions, that list could be questioned. Along with the emphasis on questioning, in Priest's account, one need only emphasize the fact that Priest's conception of philosophy holds a negative and a positive component, where the positive component may be extended to whether one contributes to some discourse and/or ongoing circumstance.

\subsubsection{COMPONENT 2: MULTIPLE CANONS, MULTIPLE METHODOLOGIES OF DISCIPLINARY VALIDATION}

\footnotetext{
${ }^{17}$ In this vein, however, other factors will still hold sway over which philosophical praxes will thrive within a given philosophy department. Yet, given the reality that at this moment in history, professional philosophy is being called to highlight its usefulness, it might behoove otherwise recalcitrant professional philosophers and philosophy departments to reevaluate the scope and role of philosophy (McIntyre 2011). For example, in a culture of praxis, graduate education in philosophy can be broadened to allow more room for the creation of philosophers with expertise in other fields of study relatively easily. Not all professional philosophers would be employed in philosophy departments, which is an already present reality for many professional philosophers. But the stigma that can follow not being employed in a philosophy department for professional philosophers might be significantly lessened.
} 
The second aspect of a culture of praxis involves the proliferation of canons and methods of disciplinary validation. On this front, Priest's definition of philosophy as criticism also does not require a single set of canonical writings. In fact, a multitude of questions will probably produce a multitude of canons. Now, where his position might appear irreconcilable to the second component of a culture of praxis is whether Priest is committed to a single method of disciplinary validation, i.e. discernable critique. This is where the culture of praxis idea might appear to be incompatible with Priest's conception of philosophy. Answers to the question, "what is philosophy," like Priest's definition, imply a delimiting perspective on disciplinary engagement. However, this is only an implication. It actually becomes a delimiting perspective if we take Priest to be offering a universalizable definition of philosophy, i.e. critique as a univocally relevant justifying norm. That is to say, within a culture of justification that admits of one set of justifying norms, Priest's account of philosophy as critique could easily become a constrictive definition of philosophy. However, in like fashion, the understanding of philosophical theorizing that follows from Lorde's observations, if taken to contain the only set of justifying norms available, would be equally constrictive. A culture of justification and its assumption of commonly held, univocally relevant justifying norms makes any understanding of philosophical engagement constrictive. Within a culture of praxis, however, Priest's definition is not universalizable. As a result, in a culture of praxis, Priest's account can be probed for the ways it is at once useful for some projects and irrelevant to others.

This second component of a culture of praxis is not a feature of philosophical theories themselves, unlike the first component. It is a component that should manifest in disciplinary environments for professional philosophy themselves. For example, Priest's understanding of philosophy as critique and the methodological validations that follow from it may prove irrelevant to positions following from a philosophical praxis based on Lorde's positions. But this does not spell disaster for Priest's understanding of philosophy; it simply gives us a sense where it, quite possibly, does not apply. That is to say, valuing multiple forms of disciplinary validation acts like a check against the universalizability of definitions of philosophy and their resulting justifying norms, which too often translates into constrictive and, at times, ethnocentric definitions of philosophy along with justifying norms that are falsely taken to be commonly held and univocally relevant. A proliferation of disciplinary validations, that map onto how one's work contributes (including methodologies that shape one's contribution and one's definition of contribution), would go far to create an environment where senses of incongruence become sites of exploration. A culture of praxis, with its value on contribution, multiple canons, and multiple forms of disciplinary validation, would be flexible enough to identify philosophical engagement according to a range of factors. As a result, a culture of praxis within professional philosophy would present a great deal more livable options than it does currently. 


\section{ACKNOWLEDGEMENTS}

I would like to thank Anita Allen for issuing the challenge to turn a critical eye toward the profession of philosophy for what it offers or fails to offer black women. Thanks also to Kyle Whyte, Jim Nelson, Sandra Harding, Marilyn Frye, the philosophy graduate students in the 2009 \& 2010 proseminars at Michigan State University (especially Samantha Noll, John Dombrowski, and Ian Werkheiser), the audience at the 2009 Ida B. Wells Philosophy Conference at the University of Memphis, and the three anonymous reviewers of Comparative Philosophy for their thought-provoking comments on various drafts of this paper.

\section{REFERENCES}

Allen, Anita L., Maaza Mann, Anika, Marcano, Donna-Dale \& Moody-Adams, Michele (2008), "Situated Black Women's Voices in/on the Profession of Philosophy", Hypatia, 23 (2): 160-189.

Bailey, Alison (1998), "Privilege: Expanding on Marilyn Frye's 'Oppression"”, Journal of Social Philosophy, 29 (3): 104-119.

Code, Lorraine (1981), "Is the Sex of the Knower Epistemologically Significant?", Metaphilosophy, 12 267-276.

Code, Lorraine (1993), "Taking Subjectivity into Account", in Linda Alcoff \& Elizabeth Potter (eds.), Feminist Epistemologies (New York: Routledge), 15-48.

Dotson, Kristie (2011), "Concrete Flowers: Contemplating the Profession of Philosophy", Hypatia, 26 (2): 403-409.

Gines, Kathryn T. (2011), "Being a Black Woman Philosopher: Reflections on Founding the Collegium of Black Women Philosophers", Hypatia, 26 (2): 429437.

Godlovitch, Stan (2000), "What Philosophy Might Be About: Some SocioPhilosophical Speculations", Inquiry, 43 (1): 3-19.

Gracia, Jorge J. E. (2000), Hispanic/Latino Identity: A Philosophical Perspective (Malden: Blackwell).

Gracia, Jorge J. E. (2008), Latinos in America: Philosophy and Social Identity (Malden: Blackwell).

Harding, Sandra (ed) (2011), The Postcolonial Science and Technology Studies Reader (Durham: Duke University Press).

Harris, Leonard (1997), "The Horror of Tradition or How to Burn Babylon and Build Benin While Reading Preface to a Twenty-Volume Suicide Note", in John P. Pittman (ed.) African-American Perspectives and Philosophical Traditions (New York: Routledge), 94-118.

Haslanger, Sally (2008), "Changing the Ideology and Culture of Philosophy: Not by Reason (Alone)", Hypatia, 23 (2): 210-223.

Jaggar, Alison M. (2000), "Ethics Naturalized: Feminism's Contribution to Moral Epistemology”, Metaphilosophy, 31 (5): 452-468. 
Jones, William R. (1977-1978), “The Legitimacy and Necessity of Black Philosophy: Some Preliminary Considerations", The Philosophical Forum, 9 (2-3): 149-160.

Kitcher, Philip (2011), "Philosophy inside Out", Metaphilosophy, 42 (3): 248-260.

Locke, Alain (1991), "Values and Imperatives", in Leonard Harris (ed.) The Philosophy of Alain Locke: Harlem Renaissance and Beyond (Philadelphia: Temple University Press), 31-50.

Lorde, Audre (1984), Sister Outsider: Essays and Speeches (Trumansburg: Crossing Press).

Lorde, Audre (2009), "Poetry Makes Something Happen", in Rudolph Bryd, Johnnetta Betsch Cole \& Beverly Guy-Sheftall (eds.), I Am Your Sister: Collected and Unpublished Writings of Audre Lorde (New York: Oxford University Press), 184-187.

Marcano, Donna-Dale L. (2010), "The Difference That Difference Makes: Black Feminism and Philosophy", in Maria Del Guadalupe Davidson, Kathryn T. Gines \& Donna-Dale L. Marcano (eds.), Convergences: Black Feminism and Continental Philosophy (Albany: SUNY Press), 53-65.

Mcintosh, Peggy (2008), "White Privilege and Male Privilege: A Personal Account of Coming to See Correspondences through Work and Women's Studies", in Alison Bailey \& Chris Cuomo (eds.), The Feminist Philosophy Reader (New York: McGraw-Hill), 61-69.

Mcintyre, Lee. (2011), "Making Philosophy Matter - or Else", The Chronicle Review, $<$ http://chronicle.com/article/Making-Philosophy-Matter-or/130029/> [Accessed $12 / 12 / 11]$.

Moulton, Janice (1996), “A Paradigm of Philosophy: The Adversary Method", in Ann Garry \& Marilyn Pearsall (eds.), Women, Knowledge, and Reality: Explorations in Feminist Philosophy (New York: Routledge), 11-25.

Nye, Andrea (1998), “ “It's Not Philosophy” ”, Hypatia, 13 (2): 107-115.

Outlaw Jr., Lucius (1996), On Race and Philosophy (New York: Routledge).

Outlaw Jr., Lucius (1997), “African, African American, Africana Philosophy", in John P. Pittman (ed.) African-American Perspectives and Phiosophical Traditions (New York: Routledge), 63-93.

Outlaw Jr., Lucius \& Roth, Michael D. (1997), "Is There a Distinctive AfricanAmerican Philosophy?", Academic Questions, 10 (2): 29-45.

Prabhu, Joseph (2001), "Philosophy in an Age of Global Encounter", APA Newsletter on Asian and Asian American Philosophers and Philosophies, 1 (1): 29-31.

Priest, Graham (2006), “What Is Philosophy?”, Philosophy, 81 189-206.

Salamon, Gayle (2009), "Justification and Queer Method, or Leaving Philosophy", Hypatia, 24 (1): 225-230.

Sanchez, Carlos (2011), "Philosophy and Post-Immigrant Fear", Philosophy and the Contemporary World, 18 (1): 31-42.

Solomon, Robert (2001), “'What Is Philosophy?' the Status of World Philosophy in the Profession", Philosophy East and West, 51 (1): 100-104.

Struhl, Karsten J. (2010), "No (More) Philosophy without Cross-Cultural Philosophy”, Philosophy Compass, 5 (4): 287-295. 
Tiwald, Justin (2008), "A Case for Chinese Philosophy", APA Newsletter on Asian and Asian-American Philosophers and Philosophies, 8 (1): 6-7.

Valian, Virginia (2005), "Beyond Gender Schemas: Improving the Advancement of Women in Academia", Hypatia, 20 (3): 198-213.

Walker, Margaret Urban (1992), "Feminism, Ethics and the Question of Theory", Hypatia, 7 (3): 23-38.

Walker, Margaret Urban (2005), “Diotima's Ghost: The Uncertain Place of Feminist Philosophy in Professional Philosophy", Hypatia, 20 (3): 153-164.

West, Cornel (1977-1978), "Philosophy and the Afro-American Experience", The Philosophical Forum, 9 (2-3): 117-148.

West, Cornel (1995), "The Black Underclass and Black Philosophers", in Fred Lee Hord \& Jonathan Scott Lee (eds.), I Am Because We Are: Readings in Black Philosophy (Amherst: University of Massachusetts Press), 356-366.

Yancy, George (1998), African-American Philosophers: 17 Conversations (New York: Routledge). 